\title{
A framework to implement Occupational health and safety innovation
}

\author{
Sara Shahedi ${ }^{1}$, Alfredo Augusto Vieira Soeiro², Sara Maheronnaghsh
}

\begin{abstract}
1Department of Mining, Faculty of Engineering, University of Porto, PT (s shahedi@yahoo.com) ORCID 0000-0001-5954-6209, 2Department of Civil Engineering, Faculty of Engineering, University of Porto, PT (avsoeiro@fe.up.pt) ORCID 0000-0003-4784-959X, ${ }^{3}$ Department of Mining, Faculty of Engineering, University of Porto, PT (up201600476@fe.up.pt) ORCID 0000-0002-4966-4292.
\end{abstract}

https://doi.org/10.24840/978-972-752-279-8_0043-0048

\begin{abstract}
Background and objectives: Being able to compete in the market needs sustainable development. Occupational safety and health Innovation process is one of the most important procedures helping companies to achieve their goal and to win the competition as radical change in the workers' environment, enhancing the profitability of companies. However, most research and discussion of innovations are focused on product development and/or process improvement, disregarding workplace and service innovation. This study will outline the general terms related to safety innovation and how the process can get managed using some techniques to implement a framework in a company. In this case, the objectives of the study are to introduce the innovation in $\mathrm{OHS}$ and to introduce a model including some techniques for industries to apply innovation in occupational safety and health. Methodology: To apply Innovation in occupational safety and health, the first step is to indicate the importance of innovation. To do so, a major review of studies focusing on occupational safety and health and innovation were required. The second step in this part is to define a frame work for innovation in safety and health, by reviewing those introduced frameworks in both innovation and health and safety researches. Results and conclusions: As a result, the importance of innovation has been searched and emphasized. On the other hand, a 6 step framework has been introduced and the details of applying the framework has been expanded. The frame work employs 6 continues steps starting by TIPS technique which is followed by JTBD. Based on the result, the framework can be applied. The introduced steps are as follow: Identifying Innovation Projects, Scoping and Focusing Innovation Projects, Leveraging Brainpower and Turbo-Charging Creativity, Selecting the Best Ideas for Further Development and Design, Evaluating How New Products/Services Perform Prior to Their Release, Problem Diagnosis and Improvement Prior to Commercialization. Following these steps as a framework may increase the efficiency of the company however, there is a huge need of several case studies in long term to assess the result and to compare the efficiency of the introduced framework.
\end{abstract}

Keywords: Innovation, Innovation management, Occupational safety, consequence analysis, gas refinery.

\section{INTRODUCTION}

Over the last few years innovation has turned out to be one amongst the foremost necessary issues for all industries (Khosravi, Newton, \& Rezvani, 2019). Baregheh (2009) described the innovation as "the multi-stage process whereby organizations transform ideas into new products, service or processes, in order to advance, compete and differentiate themselves successfully in their marketplace".

Being successful in the marketplace by organizing work to increase productivity and decrease the cost, has been a preeminent concern of business organizations. To attain and maintain competitive advantages by new methods of work organization and systems of operation, all resources and attention have been devoted to commercial and financial concerns rather than well-being, safety and health of employees (Dawson \& Zanko, 2009).

Occupational safety and health (OSH) issues recently arisen in some cases; however innovative solutions to OSH problems are absent to a great extent. According to the ILO (International Labor Organization) more than 2 million diseases and 450 million accidents are experienced annually by workplaces (Pillay, 2015). The related social and financial expenses of these accidents and diseases are anticipated to expand further as our subsequent generation of employees continues to face challenges from a range of quarters.

Managing these costs, therefore, continues to be an assignment for policy makers, practitioners and lecturers concerned in accident prevention and security management. A potential reason for this dire state of affairs is that developments in safety management are outpaced by technological advancements, and a lot of innovations are required. 
This needs scientists to change the method organizations manage safety. Doing this, however, needs us to possess a far higher understanding of however accidents are caused, how they'll be prevented or how the cost can be decreased after happening the accident, and the way safety may be managed in organizations (Pillay, 2015).

Innovation

Organizations need innovation as a sustainable source of long-term success (Camisón \& VillarLópez, 2014; Khosravi et al., 2019). Many scientists offer different definitions for innovation. A definition is to transform a new idea into a product, process, object, or service (Jilcha \& Kitaw, 2017) (O'Sullivan, 2000)

Innovation management on the other hand is related to increase the creation of knowledge to obtain or improve products, processes or services. Not only that, improving the way jobs are done to achieve the organization's goal is one of the most important ways ends in innovation management.(Simsit, Vayvay, \& Oztürk, 2014) managing innovation is a quick and adoptable way in order to overcome competitors and achieve a sustainable competitive advantage (Poolton \& Barclay, 1998).

The way to success innovation management process is only when those generated outputs could conquer barriers in order to accomplish market needs (Páez-Avilés, Juanola-Feliu, \& Samitier, 2018). Hence managers prefer to work on strategies or actions to influence the productivity and impact of their scientists and product development teams. These strategies are even more necessary when managing different technologies increases the complexity of the process (PáezAvilés et al., 2018).

The process begins with the recognition of a problem or finding an idea, extends over the problem-solving and the creation of productive capacity to the introduction of the new product or service on the market (Tidd \& Bessant, 2018).

Occupational Safety and Health Innovation

Occupational safety define as comfort of working environment for employees. It includes, but not limited to, applicability of working methods for the recommended operation and reliability of machine design. (Organization, 2002). Occupational health on the other hand, is the wellbeing of employees that protects workers from any workplace accidents in any circumstance (Jilcha, Kitaw, \& Beshah, 2016; Oeij, Dhondt, Kraan, Vergeer, \& Pot, 2012).

The research showed that a poor work environment, less pay, weak conducive and weak work environments and less experience, together with stress, tiredness, pain, boredom, demotivation and unhappiness, reduce productivity. Injuries and illnesses increase workers' compensation and retraining costs, absenteeism, and faulty products (Jilcha et al., 2016; Oeij et al., 2012).

Although the positive impact of healthy workplaces on growth is well known, some companies, small enterprises and organizations are still facing challenges in adopting preventive measures (Masi, Cagno, \& Micheli, 2014) regarding workplace hazards.

Most of a companies' focus is on the external customer satisfaction with their product or service disregarding worker satisfaction and working environment comfort in economically lagging countries. Consideration of OSH has a great impact for the development of economic growth and organizational productivity improvement (Jilcha et al., 2016). With workplace safety and health improvements, there is an increase in the health and satisfaction of employees (Nuwayhid, 2004) (Organization, 2010). Many researchers have found that wealth means health(Rufino \& Villasor, 2015). 
Innovation has been discussed by many researchers with different approaches but the final conclusion brought all ideas to a focal point as being creating new products and services or adopting the existing technology from where it was developed into a new situation. Safety innovation, however, is being disregarded and has not been discussed in many research findings. According to the literature review, occupational safety innovation is the improvement of workplace system. Which is configuring people who work there and their work environment (Beblavý, Maselli, \& Martellucci, 2012; Jilcha et al., 2016; Oeij et al., 2012; Podgórski, 2015)

Due to importance of employees' well-being and to decrease the lack of innovation in OSH, the main goal of this paper is 1) to introduce the innovation in OHS and 2) to introduce a model including some techniques for industries to apply innovation in occupational safety and health.

\section{METHODOLOGY}

Innovation Management Process

Initiation of innovation process is defining the jobs need to be done and the target group. Phases of the process has shown in the diagram below.

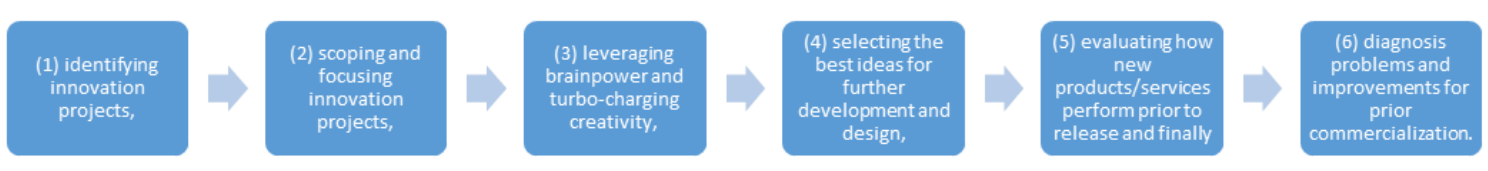

Figure 1. Steps of innovation process.

The first step of the process is to find out and uncover the target group's needs. Following that segments of opportunities need to find, market opportunity sized, competitive analysis conducted, innovation and pricing strategies formulated. Completing these analysis leads the process to define and assess the solution. Following these steps can be done by using some tools and techniques selected based on the structure of the industry, target group and type of the service.

\section{Identifying Innovation Projects}

Defining the needs of the target group is the start point of the innovation project. Among several techniques enabling one to create innovation opportunities, job to be done (JTBD) process is a revolutionary concept that guides toward innovation and helps move beyond the norm of only improving current solutions (Silverstein, Samuel, \& DeCarlo, 2013). There are 6 steps for JTBD process which are (1) Identify a Focus Market, (2) Identify Jobs Customers Are Trying to Get Done, (3) Categorize the Jobs to be Done, (4) Create Job Statements, (5)Prioritize the Opportunities and (6) Identify Outcome Expectations Regarding the job (Simsit et al., 2014).

\section{Scoping and Focusing Innovation Projects}

Scoping and focusing innovation projects can be seen as a redefinition problem. From this point of view "Heuristic redefinition" can help a team to visualize the various elements of a problem as well as its underlying structure (Simsit et al., 2014).

One of the techniques to scope and focus innovation projects is Theory of Inventive Problem Solving (TIPS). This theory is an international system of creativity developed by the Soviet inventor and science-fiction author Genrich Altshuller (1926-1998) (Barry, Domb, \& Slocum, 2010).

According to TIPS, universal principles of creativity form the basis of innovation. TIPS identifies and codifies these principles, and uses them to make the creative process more predictable ("A Powerful Methodology for Creative Problem Solving," 2019). 
Heuristic Ideation is a very efficient group technique that helps to generate new and innovative ideas. The participants compare two items or concepts that are not apparently related (McFadzean, 2002). In order to implement this technique two items of interest that are already in existence but are not connected need to be chosen.

\section{Selecting the Best Ideas for Further Development and Design}

The KJ Method was developed as the Affinity Diagram by Jiro Kawakita in the 1960s and has become one of the Seven Management and Planning Tools used in Total Quality Control. It provides a way to organize and refine innovation ideas, sparking further dialogue and achieving consensus about which ideas are worth developing. In advance of the idea-generating session, participants receive a description of the challenge, posting the JTBD associated outcome expectations so the team can keep these in mind (Simsit et al., 2014).

Forming a team around 4-6 and including the stakeholders or the ones who lives the problem will create better ideas during development stage. After all ideas created and posted by all participants giving more time to the participants will create time to everyone to submit more ideas inspired by the first round of ideas. This is called YES\&AND activity.

The next step is sorting the ideas into related categories based on functionality, features, outcome or whatever makes sense and voting on ideas. Each team member gives 3 to 5 votes to place on the same or multiple ideas. The idea with the most votes merit further discussion and/or development. KJ method allows free and creative thinking and frees everyone from problem so that can pursue creative thinking based on facts without any constraints (Simsit et al., 2014).

Evaluating How New Products/Services Perform Prior to Their Release

A prototype is an early sample, model or release of a product built to test a concept or process or to act as a thing to be replicated or learned from. This term used in a variety of contexts, including semantics, design, electronics, and software programming. A prototype is designed to test and trial a new design to enhance precision by system analysts and users (Simsit et al., 2014). Prototyping serves to provide specifications for a real, working system rather than a theoretical one. It also tests the robustness of design and its sensitivity to uncontrollable factors (Hernley, 2011).

One of the most common pitfalls is the tendency to wait until they have everything right before sharing their prototype with others. Ironically, the primary reason of prototyping is to communicate ideas and get feedback to validate project requirements. It's human nature to want that prototype to be "perfect" before showing it to anyone (Simsit et al., 2014).

Prototyping lets visual communication and interactive design concepts to both team members and non-technical stakeholders so that constructive feedbacks can gather earlier in the process when it's most valuable. A prototype to validate existing requirements, uncover missing requirements, help to clients understand exactly what they need, and ensure that correct designing based on correct assumptions. Repeated sharing, gathering feedbacks and refining prototypes through as many cycles are required to reach a right decision. Each cycle turns the dial, bringing the customer's needs, and the project itself, into clearer and clearer focus(Taiwo, 2010).

Problem Diagnosis and Improvement Prior to Commercialization

A Control Plan provides a single point of reference for understanding process characteristics, specifications, and standard operation procedures also known as SOP for the process. A control 
plan enables assignment of responsibility for each activity within the process. This ensures that the process is executed smoothly and is sustainable in the long run (Poots \& Woodcock, 2012). Control Plan is critical to ensuring that your innovation will be produced or delivered according to your careful design, regardless of location, personnel, environment or other variables that you won't be able to control (Silverstein et al., 2013).

One of the important points to consider in implementing innovation models is that these models are non-linear and may be referred to several previous or subsequent steps at each step. Therefore, implementation of such models cannot easily done step by step and also the margin between different steps cannot be clearly clarified.

\section{RESULTS AND CONCLUSION}

In 21th century the importance of innovation is not hidden for anyone specially managers trying to win the market competition. Innovation is not only employing new tools, services and process, but also any changes in a way a process has been done to gain the goal would consider as an innovation.

Innovation management can be used to develop both product and organizational innovation and includes a set of tools that allow managers and engineers to cooperate with a common understanding of goals and processes. It is an obvious necessity that managers need a clear road map in innovation management which is a complex procedure especially because of the characteristic of innovation itself.

Companies who started improvements before and accelerated technology transfer continuously gain advantages among its rivals. On the other hand companies who are just starting their development process in terms of innovation management had to move forward with right steps because there is already a gap between their rivals.

Nowadays, among several industrial challenges, one that clearly stands out in emerging economies is occupational safety and health specifically. These challenges are expected to be reduced through innovative researches and implementation of the research output models. Thus, workplace safety and health consideration has had less attention in developing countries as stated and evidenced by different researches. Most of a company's focus is on the external customer satisfaction with their product or service disregarding worker satisfaction and working environment comfort in economically lagging countries.

Consideration of $\mathrm{OSH}$ has a great impact for the development of economic growth and organizational productivity improvement. With occupational safety and health improvements, there is an increase in the health and satisfaction of employees. Many researchers have found that wealth means health. In solving these problems, one of the most important starting points is innovative development of the occupational safety and health improvement systematic approach. Workplace design and hazards interventions have been identified as barriers in manufacturing industries which need innovation.

This study followed a 6-step framework to implement innovation process in any industry by focusing on safety approaches. The framework. Although implementing of safety innovation frame work may increase the efficiency of the company, the framework itself needs a long period of time to get assessed specially for its 2-last step. 


\section{References}

Baregheh, A. (2009). Towards a multidisciplinary definition of innovation. Management Decision, 47(8), 1323-1339. doi:10.1108/00251740910984578

Barry, K., Domb, E., \& Slocum, M. (2010). TRIZ-What Is TRIZ? The Triz Journal. Real Innovation Network. In.

Beblavý, M., Maselli, I., \& Martellucci, E. (2012). Workplace Innovation and Technological Change. CEPS Special Reports, Forthcoming.

Camisón, C., \& Villar-López, A. (2014). Organizational innovation as an enabler of technological innovation capabilities and firm performance. Journal of Business Research, 67(1), 2891-2902.

Dawson, P. M., \& Zanko, M. (2009). Reframing occupational health and safety management: a social innovation approach.

Hernley, L. R. (2011). An analysis of early stage prototypes using implementation, look and feel, and role. Massachusetts Institute of Technology,

Jilcha, K., \& Kitaw, D. (2017). Industrial occupational safety and health innovation for sustainable development. Engineering Science and Technology, an International Journal, 20(1), 372-380. doi:https://doi.org/10.1016/j.jestch.2016.10.011

Jilcha, K., Kitaw, D., \& Beshah, B. (2016). Workplace innovation influence on occupational safety and health. African Journal of Science, Technology, Innovation and Development, 8(1), 33-42. doi:10.1080/20421338.2015.1128044

Khosravi, P., Newton, C., \& Rezvani, A. (2019). Management innovation: A systematic review and meta-analysis of past decades of research. European Management Journal. doi:https://doi.org/10.1016/j.emj.2019.03.003

Masi, D., Cagno, E., \& Micheli, G. J. (2014). Developing, implementing and evaluating OSH interventions in SMEs: a pilot, exploratory study. International journal of occupational safety and ergonomics, 20(3), 385-405.

Nuwayhid, I. A. (2004). Occupational health research in developing countries: a partner for social justice. American Journal of Public Health, 94(11), 1916-1921.

O'Sullivan, M. (2000). The innovative enterprise and corporate governance. Cambridge Journal of Economics, 24(4), 393-416.

Oeij, P., Dhondt, S., Kraan, K., Vergeer, R., \& Pot, F. (2012). Workplace Innovation and its Relations with Organisational Performance and Employee Commitment-www-publicatie.

Organization, W. H. (2002). The world health report 2002: reducing risks, promoting healthy life: World Health Organization.

Organization, W. H. (2010). World health statistics 2010: World Health Organization.

Páez-Avilés, C., Juanola-Feliu, E., \& Samitier, J. (2018). Cross-fertilization of Key Enabling Technologies: An empirical study of nanotechnology-related projects based on innovation management strategies. Journal of $\begin{array}{lllll}\text { Engineering and } \quad \text { Technology } & \text { 22-45. }\end{array}$ doi:https://doi.org/10.1016/j.jengtecman.2018.05.001

Pillay, M. (2015). Accident Causation, Prevention and Safety Management: A Review of the State-of-the-art. Procedia Manufacturing, 3, 1838-1845. doi:https://doi.org/10.1016/j.promfg.2015.07.224

Podgórski, D. (2015). Measuring operational performance of OSH management system-A demonstration of AHPbased selection of leading key performance indicators. Safety science, 73, 146-166.

Poolton, J., \& Barclay, I. (1998). New product development from past research to future applications. Industrial Marketing Management, 27(3), 197-212.

Poots, A. J., \& Woodcock, T. (2012). Statistical process control for data without inherent order. BMC Medical Informatics and Decision Making, 12(1), 86.

A Powerful Methodology for Creative Problem Solving. (2019). Retrieved from https://www.mindtools.com/pages/article/newCT_92.htm

Rufino, C. C., \& Villasor, R. S. (2015). Health is Wealth.

Silverstein, D., Samuel, P., \& DeCarlo, N. (2013). The innovator's toolkit: 50+ techniques for predictable and sustainable organic growth: John Wiley \& Sons.

Simsit, Z. T., Vayvay, O., \& Oztürk, O. (2014). An Outline of Innovation Management Process: Building a Framework for Managers to Implement Innovation. Procedia - Social and Behavioral Sciences, 150, 690-699. doi:https://doi.org/10.1016/j.sbspro.2014.09.021

Taiwo, A. S. (2010). The influence of work environment on workers productivity: A case of selected oil and gas industry in Lagos, Nigeria. African Journal of Business Management, 4(3), 299-307.

Tidd, J., \& Bessant, J. R. (2018). Managing innovation: integrating technological, market and organizational change: John Wiley \& Sons. 